\title{
Call for Papers Announced for 1985 Fall Meeting
}

A call for papers has recently been issued for topical symposia being conducted during the 1985 MRS Fall Meeting to be held in Boston, December 1-6. Program chairpersons, John Baglin, Dave Biegelsen, and John Fan indicate that this year's meeting is anticipated to be larger than last year's meeting by more than $25 \%$.

"We are extremely pleased to see so many opportunities for exchange of ideas on so many important topics," Baglin said. "This meeting features 22 topical symposia, including a number which are continuations in a series of highly popular MRS symposia, as well as some new innovative forums."

In addition to the top-level content of the symposia, according to Biegelsen, much work has gone into ensuring that timetables

\section{Symposium $A$ \\ BEAM-SOLID INTERACTIONS AND PHASE TRANSFORMATIONS}

This symposium is devoted to the fundamental aspects of beam-solid interactions and beam-induced phase transformations in materials. The symposium provides an interdisciplinary forum for scientists engaged in research on the interaction of photon, ion, and electron beams with solids and the thermodynamics and kinetics of rapid phase transformations between mestastable and stable states. Specific areas in which papers are solicited include

- Laser-solid interactions and ultrafast energy transfer

- laser-induced melting and rapid solidification (crystal growth, amorphization, impurity segregation, interface instability)

- Kinetics and thermodynamics of phase transformations in amorphous layers (epitaxy, random crystallization, impurity diffusion and precipitation)

- Beam induced epitaxy

- Ion and electron beam-solid and beam-surface interactions: chemistry and phase changes.

Symposium Chairpersons

H. Kurz, Technical Univ. Aachen, Inst. Semicond. Electron., D-5100 Aachen, Fed. Rep. Germany, 011-49-241-807745

G. L. Olson, Hughes Research Laboratories, 3011 Malibu Cyn. Rd., Malibu, CA 90265, (213) 317-5457

J. M. Poate, AT\&T Bell Labs., 600 Mountain Ave., Murray Hill, NJ 07974, (201) 582-3462

\section{Symposium B}

\section{RAPID THERMAL PROCESSING}

This symposium is new this year and will bring together studies utilizing large area incoherent energy sources for transient thermal processing of semiconductor materials. The symposium will place emphasis on fundamental issues of materials modification in short time intervals at elevated temperatures. Because of the considerable commercial potential of rapid thermal processing (RTP), an emphasis is also placed on studies of electrical characteristics and device performance of materials and structures so processed. Papers are solicited in the following areas:

- Temperature measurement and rapid thermal processor design

- Diffusion, enhanced diffusion and impurity redistribution

- Annealing of ion implant damage in Si and compound semiconductors

- Defect and structural evaluation

- Dopant redistribution in silicide/Si structures

- Metal semiconductor contacts and interconnects

- Oxide, oxynitride, nitride formation and annealing

- Glass reflow, gettering and related VLSI processing

- Device performance and electrical characteristics

Symposium Chairpersons

T. O. Sedgwick, IBM, T. J. Watson Research Center, P.O. Box 218 ,

Yorktown Hts., NY 10598, (914) 945-2013

T. E. Siedel, J. C. Schumacher Co., 580 Airport Road, Oceanside, CA 92054, (619) 433-1663 for sessions are coordinated to minimize concurrency of presentations in areas of common interest. "And," he emphasized, "this year's expanded equipment exhibit adds another valuable dimension to the meeting."

A detailed call for papers brochure is being mailed to MRS members and other interested persons with complete instructions for preparation of abstracts. For further details, contact the appropriate symposium chairperson. Fan pointed out that the deadline for receipt of abstracts is June 14,1985, unless otherwise indicated.

For further information on participating in the equipment exhibit, contact American Institute of Physics, 335 East 45th Street, New York, NY 10017, telephone (212) 661-9404, Attention: Ed Greeley.

B.-Y. Tsaur, MIT Lincoln Lab, P.O. Box 73, Lexington, MA $02173-$ 0073, (617) 863-5500 ext. 4472

\section{Symposium $C$}

\section{SEMICONDUCTOR ON INSULATOR AND THIN FILM TRANSISTOR TECHNOLOGY}

The purpose of this symposium is to critically assess new developments in the rapidly progressing technologies involving semiconductors on insulators. The symposium will provide an international forum for scientists and engineers engaged in thin film semiconductor crystal growth either by solidification following beam-melting, solid phase epitaxy, lateral epitaxial overgrowth, heteroepitaxy, or chemical vapor deposition. SOI structures formed by implantation of oxygen or nitrogen or those formed with oxidized porous silicon are also included. The semiconductors may include III-V, II-VI, group IV or organic materials, and may be either single or polycrystalline. The symposium will emphasize materials technology as well as relevant device and circuit issues. Papers on novel structures such as those employing optically active substrates or structures with buried metals as in metal base transistors are encouraged. Papers pertaining to SOI/TFT are solicited in the following areas:

- Materials growth

- Origins and characterization of defects

- Interlayer materials compatibility

- Low temperature processes

- Novel materials or devices

- evice and circuit performance

- 3-dimensional devices

- Yield and uniformity

- Displays - image sensors - high voltage, high-power, high-speed and high-density applications

Symposium Chairpersons

Anne Chiang, Xerox PARC, 3333 Coyote Hill Rd., Palo Alto CA 94304, (415) 494-4212

Michael W. Geis, Lincoln Lab, MIT, P.O. Box 73

Lexington, MA 02173, (617) 863-5500, ext. 4685

Loren Pfeiffer, AT\&T Bell Labs., Inc.

Rm. IC-445, Murray Hill, NJ 07974 (201) 582-2910

\section{Symposium D}

\section{BEAM INDUCED CHEMICAL PROCESSES}

This symposium will feature work using any type of directed energy beam to enhance chemical processes at surfaces. The symposium is an extension of several earlier symposia on the use of lasers for the processing and modification of microelectronic materials. Special emphasis will be placed on fundamental effects occurring at the surface on an atomic scale, enhanced by a directed energy beam. Also, the use of these beams to enhance the growth and removal of materials of interest to microelectronic applications will be discussed. Topics will include beam-surface effects to enhance interaction with gases and liquids in metals, semiconductors and insulators, particularly polymers. Topics for which papers are solicited include: 
- Fundamental surface processes with directed energy beams: energy beam-surface interactions and enhanced chemistry, physi and chemisorption-desorption surface interactions, diagnostics of energy beam processes and interactions

- Wet and dry chemistry of maskless beam assisted deposition and material removal: pyrolitic, photochemical and photothermal deposition and etching of metals, semiconductors and insulators; beam enhanced plasma effects; alloying; modeling

- Applications of directed energy beams, circuit repair, alteration and

design, redundancy techniques, solar cells, gratings

Symposium Chairpersons

*R. J. von Gutfeld, IBM Watson Research Ctr., P.O. Box 218,

Yorktown Heights, NY 10598, (914) 945-1534

J. E. Greene, Co-ordinated Science Lab, Univ. of Illinois,Urbana, IL 61801, (217) 333-0747

H. Schlossberg, AFOSR, Bolling AFB, Washingtoin, DC 20332, (202)

\section{7-4906}

"Forward abstracts to this chairperson.

\section{Symposium E}

\section{THIN FILMS-INTERFACES AND PHENOMENA}

This symposium will address the properties of thin films with respect to the interactions of interfaces and related phenomena. Both theoretical and experimental contributions are invited. While the conference will continue to focus on structural, electronic and chemical properties, contributions which correlate these aspects with macroscopic properties such as stress, conductivity or the Schottky barrier are encouraged. Silicide formation and interface proper ties will continue to be emphasized but contacts to compound semiconductors involving silicides and related materials will also be included, as well as epitaxial structures on silicon and related device structures. Ion beam effects, silicide oxidation and other effects related to VLSI technology will also be addressed. Papers are solicited in the following areas:

- Interface reactions and kinetics

- Ion beam mixing and reactions in thin films

- Epitaxial silicides and insulators

- Metastable phase formation

- Structure and electronic properties

- Electrical properties: Schottky barrier, Ohmic contacts

- Contacts to semiconductors

- Silicides on compound semiconductors

- Analysis, characterization, growth

- Oxidation and passivation

- Interconnects, metallization and packaging

Symposium Chairpersons

R. J. Nemanich, Xerox PARC, 3333 Coyote Hill Rd., Palo Alto, CA 94304, (415) 494-4169

S. S. Lau, Dept. Elec. Eng. \& Comp. Sci., C-014, U. of California, San Diego, La Jolla, CA 92093, (619) 452- 3097

P.S. Ho, IBM Watson Research Ctr., P.O. Box 218, Yorktown Heights, NY 10598, (914) 945-2007

\section{Symposium $F$}

\section{TRANSPORT AND EXCITATION IN POLYMERS}

This symposium will provide an interdisciplinary forum for the interaction and exchange of ideas of physicists, chemist and material scientists engaged in frontier research on polymers. The thrust of the symposium will be on the science and applications of polymers involving excitation and transport. The topics to be covered are:

- Polymer-polymer in terdiffusion

- Small molecule diffusion in polymers

- Charge transport (in insulating, semiconducting, metallic and ionconducting polymers)

- Field-induced effects (piezoelectricity, pyroelectricity and nonlinear optics)

- Excitation transport

- Radiation (photons, electrons, ion and x-ray) effects

Symposium Chairpersons

T. Venkatesan, 1E-347, Bell Communications Research, Murray Hill, NJ 07974

E. Kramer, Dept. of Materials Science and Engineering, Bard Hall, Cornell University, Ithaca, NY 14853

R. H. Baughman, Allied Corporation, P.O. Box 1021 R, Morristown, NJ 07960
Symposium $G$

\section{BIOMEDICAL MATERIALS}

The Materials Research Society is pleased to announce its first Symposium on Biomedical Materials. In recent years, new materials processing techniques and methods of analysis have equipped the materials scientist $/$ engineer as never before to respond to the unique challenges posed by in-vivo applications of materials, while exciting developments in biomedical engineering have practically become daily news. Contributed papers are solicited under two broad categories of topics:

- Materials-related design considerations in bioengineering areas such as neuroprosthetics, cardiovascular devices, orthopaedics, and opthalmology

- Responses of the field of materials science and engineering to bioengineering needs; including topics in bulk properties of candidate materials, corrosion and other surface properties of candidate materials, design and properties of composites, adhesion and interface properties of dissimilar materials, interface properties of materials and tissue, performance testing and modeling, special treatments designed to improve performance, and related basic physics, chemistry, and mechanics of materials.

Symposium Chairpersons

M. F. Nichols, Dalton Research Ctr., Research Park, Univ. of Missouri, Columbia, MO 65211, (314) 882-3837

J. M. Williams, Solid State Division, Oak Ridge Nat'1. Lab., Oak Ridge, TN 37831, (615) 574-6265

W. Zingg, Hospital for Sick Children, 555 University Ave., Toronto, Ontario M5G 1X8, (416) 598-6449 a.m., (416) 978-3114 p.m.

\section{Symposium $H$}

\section{LAYERED STRUCTURES AND EPITAXY}

Through the growth and characterization of high-quality thin films and layered structures employing epitaxy and related techniques, unique systems with both exciting physical properties and technological applications are fabricated. This symposium will bring together scientists and engineers representing all three aspects of this important field-growth, characterization and properties. Particular areas in which contributed papers are solicited include:

- Quantum well structures and superlattices

- Strained layer superlattices

- Stability of layered structures

- Epitaxy

- Epitaxial silicides and insulators

- Superconductivity

- Correlation of structure and properties

- Magnetic superlattices

- Natural superlatticess

- Electron microscopy of superlattices

- Microscopic structure of semiconductor alloys

- Elastic strain effects

- Theory and modeling

Symposium Chairpersons

J. M. Gibson, AT\&T Bell Labs, 600 Mountain Ave., Room 1E-234, Murray Hill, NJ 07974, (201) 582-5952

G. C. Osbourn, Sandia National Labs., Division 1132, Albuquerque, NM 87185, (505) 844-8850

R. M. Tromp, IBM T. J. Watson Research Center, P.O. Box 218, Yorktown Heights, NY 10598, (914) 945-1242

Symposium I

Symposium in Honor of Professor David Turnbull PHASE TRANSITIONS IN CONDENSED SYSTEMSEXPERIMENTS AND THEORY

The symposium will highlight Professor Turnbull's contributions as both scientist and teacher on the occasion of his 70th birthday and of his becoming professor emeritus at Harvard. The symposium will concentrate on those areas where Professor Turnbull has made his greatest contributions: nucleation, diffusion in solids, glass formation, and crystal growth. 
Symposium Chairpersons

G. S. Cargill, III, IBM Corporation, Old Orchard Road, Armonk, NY 10504, (914) 765-7510

F. Spaepen, Harvard University, Pierce Hall, Cambridge, MA 02139, (617) $495-3760$

K.-N. Tu, IBM T. J. Watson Res. Center, P.O. Box 218, Yorktown Heights, NY 10598, (914) 945-1602

\section{Symposium J \\ RAPIDLY SOLIDIFIED ALLOYS: MAGNETIC AND MECHANICAL PROPERTIES}

This symposium is the third in a biennial series on important current aspects of alloys prepared by rapid solidification processing (RSP), including metallic glasses, metastable crystalline phases, ext ended solid solutions and particle size modified structures. Emphasis will be on research in major areas of present and future application of RSP alloys, such as magnetic and mechanical materials, and on fundamental and processing considerations. The program seeks to bring together physicists, materials scientists, and engineers for an interchange of ideas and information. Contributed papers are sought; they are preferred in (but not limited to) the following principal categories:

- Fundamentals/processing (rapid solidification, metastable phases formation, surface treatment, consolidation)

- Magnetic materials and their properties (amorphous, crystalline, soft and hard magnetic alloys, structure-property relationships)

- Mechanical materials and their properties relationships, $\mathrm{Al}-, \mathrm{Ni}-, \mathrm{Ti}-$ base alloys)

Symposium Chairpersons

B. C. Giessen, Materials Science Division, Barnett Institute, Northeastern University, Boston MA 02115, (617) 437-2827

D. E. Polk, Code 431, Office of Naval Research, Arlington, VA 22217, (202) 696-4402

A. E. Taub, GE Corporate Research and Development, P.O. Box 8 , Schenectady NY 12301, (518) 385-8465

\section{Symposium $K$ \\ OXYGEN, CARBON, HYDROGEN, AND NITROGEN IN CRYSTALLINE SILICON}

This symposium focuses on the behavior of the technologically important non-dopant, light element impurities in silicon: $\mathrm{O}, \mathrm{C}, \mathrm{H}$, and $\mathrm{N}$. It is the intent of this symposium to bring together experts who understand the materials science underlying the complex processes involving these impurities. Specific areas relating to $\mathrm{O}, \mathrm{C}, \mathrm{H}$, and $\mathrm{N}$ in $\mathrm{Si}$, in which papers are solicited, include:

- Impurity incorporation during crystal growth: microscopic inhomogeneity, magnetic stirring, ribbon $\mathrm{Si}, \mathrm{SOI}$

- Intrinsic and extrinsic solubility and diffusivity

- Advances in characterization techniques for $\mathrm{O}, \mathrm{C}, \mathrm{H}, \mathrm{N}$

- Aggregation phenomena, including clustering, complexing, thermal donors, and especially precipitation

- Mechanism and stability of internal gettering

- $\mathrm{O}, \mathrm{C}, \mathrm{H}$, and $\mathrm{N}$ interaction with structural defects

- Mechanical properties, such as critical shear stress

Chairpersons

J. W. Corbett, Dept. of Physics, SUNY at Albany, Albany, NY 12222, (518) 457-8315

J. C. Mikkelsen, Jr. Xerox PARC, 3333 Coyote Hill Rd., Palo Alto, CA 94304 (415) 494-4917

S. J. Pearton, AT\&T Bell Labs. 7D-413, 600 Mountain Ave., Murray Hill, NJ 07974, (201) 582-4757

S. J. Pennycook, Solid State Division, Oak Ridge National Laboratory, Oak Ridge, TN 37830, (615) 574-5504

\section{Symposium $L$ DEFECT PROPERTIES AND PROCESSING OF HIGH- TECHNOLOGY NONMETALLIC MATERIALS}

Increased understanding of the relationships between defects and physical properties of nonmetallic materials has already reaped many benefits in high technology. This symposium focuses on new fundamental knowledge and on new opportunities and challenges facing high-technology nonmetallic materials. Materials of interest include oxides, carbides, nitrides, and halides. This conference is the second in a series of MRS symposia devoted to the dissemination of scientific information in the rapidly expanding field of hightechnology nonmetallic materials. Papers are solicited in the following areas:

- Materials preparation and characterization

- Laser materials and optical devices

- Advanced processing methods, especially microwave sintering

- Mechanical and electrical properties

- Grain boundaries and dislocations

Symposium Chairpersons

Y. Chen, Solid State Division, Oak Ridge National Laboratory, P.O. Box $X$, Oak Ridge, TN 37831, (615) 574-6284, FTS 624-6284

W. D. Kingery, Dept. of Materials Science and Eng., MIT, Rm. 13-4090, 77 Massachusetts Ave., Cambridge, MA 02139, (617) 253-3319

R. J. Stokes, Honeywell, Inc., Physical Sciences Center, 10701 Lyndale Avenue South, Bloomington, MN 55420 (612) 887-6482

\section{Symposium $M$}

\section{OXIDES, ZEOLITES AND CLAYS IN CATALYSIS}

This symposium will focus on the preparation, properties and characterization of oxides, zeolites and clays used in various catalytic processes. Both crystalline and amorphous oxides will be covered. Less emphasis will be placed on the catalytic reactions themselves. Sections of the symposium will be devoted to oxidation catalysts and to pillared clays. Emphasis will be placed on newer methods of characterization, and the preparation of novel materials.

\section{Symposium Chairpersons}

D. E. W. Vaughan, Exxon Research \& Engrg. Co., Annadale, NJ 08801

A. Sleight, E. I. du Pont de Nemours \& Co., Inc., CRND Dept., Experimental Station, Bldg. 356, Wilmington, DE 19898, (302) 772-3536

\section{Symposium $N$ \\ FRACTAL ASPECTS OF MATERIALS}

This symposium is to provide an international forum for scientists engaged in the applications of fractal geometry in materials research and related topics. Some speakers will offer evidence on the suitability of fractals in the description of diverse materials. Other speakers may either draw practical consequences from the suitability of fractals, or attempt to explain it on the basis of fundamental mechanisms.

Symposium Chairpersons

Robert Laibowitz, IBM Research Center, P.O. Box 218, Yorktown Heights, NY 10598, (914) 945-2166

Benoit B. Mandelbrot, Mathematics, Room 512, Harvard University, Cambridge, MA 02138, (617) 495-4757

Dann E. Passoja, 410E. 73 Street, New York, NY 10021 (212) 517-9424

\section{Symposium 0}

\section{NONLINEAR OPTICAL MATERIALS}

Future applications of nonlinear optics will depend critically on advances in materials. This interdisciplinary symposium will address progress in the growth and understanding of nonlinear optical materials, and it will serve as a forum for discussion of the requirements on materials for applications, the capabilities of existing and emerging materials, and the limitations imposed by current technology. Specifically, the symposium will cover:

- Classes of nonlinear materials including: organic dielectrics, inorganic dielectrics, semiconductors, synthetic microstructures and photorefractive materials.

- Nonlinear optical effects including: electro-optical phenomena, all optical effects (such as harmonic generation, nonlinear refraction and absorption), and photorefraction.

- Factors in engineering materials for specific applications including: crystal quality, damage resistance, response times, magnitude of nonlinearity, fabrication for integrated optics, and opto-electronics. 
Symposium Chairpersons

A. M. Glass, Rm. 1A155, AT\& T Bell Labs., 600 Mountain Ave., Murray Hill, NJ 07974, (201) 582-2463

D. A. B. Miller, Rm. 4B417, AT\&T Bell Labs. Crawfords Corner Rd. Holmdel, NJ 07733, (201) 949-5458

C. L. Tang, Dept. of Electrical Engineering, Cornell University, Ithaca, NY 14853, (607) 256-5120

\section{Symposium $P$}

\section{DEFECTS IN GLASSES}

Contributed papers are solicited for this symposium concerning microscopic defects in inorganic amorphous materials, excluding amorphous $S$ and $\mathrm{Ge}$ and amorphous metals. The materials of in terest therefore include oxide-, nitride-, halide-, and chalcogenide bulk glasses, fibers and amorphous thin films. Also of interest are microscopic defects associated with the surfaces and interfaces of these materials. For this symposium, a defect is any significant departure from the idealized continuous random network model appropriate for the nominal chemical composition. The intrinsic or deliberately induced defects of interest therefore include:

- Impurities and dopants (atomic, ionic, molecular...)

- Point defects (dangling bonds, wrong bonds...)

- Extended defects (disclinations, internal surfaces...)

- Intermediate range order (rings, rafts; cages...)

A central theme for the symposium will be the nature of deviations or extensions from the continuous random network model. Contributed presentations may emphasize many aspects of defects, including experimental and theoretical studies of structure, bonding, modeling, kinetics, methods of characterization, mechanisms of formation, computer simulation, and relation to device performance.

Symposium Chairpersons

Frank L. Galeener, Xerox Palo Alto Research Center, 3333 Coyote Hill Road, Palo Alto, CA 94303, (415) 494-4110

"David L. Griscom, Code 6570, Naval Research Laboratory, Washington, DC, 20375-5000, (202) 767-2270

Marvin J. Weber, Division of Materials Science, Office of Energy Sciences, U. S. Department of Energy, Washington, DC 20545, (301) 353-3426

-Forward abstracts to this chairperson.

\section{Symposium $Q$}

\section{MATERIALS PROBLEM SOL VING WITH THE} TRANSMISSION ELECTRON MICROSCOPE

This second MRS TEM Symposium will focus on solving materials problems with the electron microscope.

\section{Symposium Chairpersons}

Linn W. Hobbs, MIT, Room 13-4066, Cambridge, MA 02139, (617) 253-6835

Ken H. Westmacott, MMRD B72, University of California, Lawrence Berkeley Laboratory, Berkeley, CA 94087, (415) 486-5663

David B. Williams, Dept. of Metallurgy \& Mat. Sci., Whitaker Lab No. 5, Lehigh University, Bethlehem, PA 18015, (215) 861-4224

\section{Symposium $R$ \\ COMPUTER-BASED MICROSCOPIC DESCRIPTION OF THE STRUCTURE AND PROPERTIES OF MATERIALS}

This symposium will provide a forum for the discussion of recent progress in microscopic descriptions of static and dynamic properties of materials by large-scale computation. Crystalline and non-crystalline solids, semiconductors, metals, insulators, ceramics, and polymeric materials will be included. Specific topics of interest include materials growth, interfaces, disordered structures, phase transitions, diffusion, defects (vacancies, interstitials, impurities), extended defects (dislocations, grain boundaries). Techniques of interest include solving the Schrodinger equation and minimizing the total energy, molecular dynamics and Monte Carlo simulations, solving Boltzmann's equation, scattering and diffraction theory, continuity equations for diffusion profiles, etc. Additional objectives will be to identify those areas in which methodological and technological innovation (e.g., special-purpose computers) are necessary for significant progress.

\section{Symposium Chairpersons}

Jeremy Broughton, Dept. of Materials Science \& Engineering, 314 Old Engineering Bldg., Stonybrook, NY 11794, (516) 246-6754

William Krakow, IBM Thomas J. Watson Research Center, P.O. Box 218, Yorktown, NY 10598 (914) 945-1759

Sokrates T. Pantelides, IBM Thomas J. Watson Research Center, P.O. Box 218, Yorktown, NY 10598 (914) 945-1207

\section{Symposium $S$}

\section{CEMENT-BASED COMPOSITES: STRAIN RATE EFFECTS ON FRACTURE}

There is increasing interest in the effects of strain rate on the fracture of cementitious composites. Materials properties at high strain rates are not the same as they are under quasi-static rates of loading; however, they must be understood when trying to design for impact or blast loading. This symposium will provide a forum to discuss material properties, design considerations, and experimental methods for determining strain rate effects. Topics considered appropriate for this symposium include, but are not limited to, the following:

- Strain rate effect on material properties

- Experimental techniques

- Design considerations

- Impact loading

- Blast loading

- Variable strain rate experiments

- Stress corrosion

- Slow crack growth

- Fracture mechanics considerations

Symposium Chairpersons

${ }^{*}$ S. Mindess, Department of Civil Engineering, 2324 Main Mall, University of British Columbia, Vancouver, B.C., V6T1W5, Canada, (604) 228-4471

S. P. Shah, Department of Civil Engineering, Northwestern University, Evanston, IL 60201-9990, (312) 492-3257

*Forward abstracts to this chairperson

\section{Abstract deadline: June 1}

\section{Symposium $T$ \\ FLY ASH AND COAL CONVERSION BY-PRODUCTS: CHARACTERIZATION, UTILIZATION AND DISPOSAL}

This symposium is the fourth in the MRS symposia series dealing with characterization, utilization and disposal of fly ash and other by-products of coal combustion and conversion (bottom ash, boiler slag, gasification ash, etc.) A continuing feature of these symposia has been the emphasis on use of modern materials characterization tools (XRD, SEM, DTA/DSC/TGA, etc.) to understand the structure, properties and reactions of these materials during utilization or disposal. This symposium will expand its scope to include papers on inorganic constituents of coal, the precursors for these materials and on the specifics of ash formation through combustion or conversion. Papers relating the collection of the ash (especially fly ash) and its influence on the nature of the ash will also be included. Only with this more comprehensive study of the materials themselves can we adequately explain and predict the relevant physical properties and chemical reactions that control the utilization or disposal of coal by-products. Papers are solicited in the following areas

- Inorganic constituents of coal and their role in ash formation

- Coal combustion and fly ash collection

- Fly ash and coal conversion ash characterization

- Fly ash beneficiation

- Reactions and microstructures

- Durability of concrete containing fly ash

- Utilization

- Disposal

- Economics of by-product utilization

Symposium Chairperson

G. J. McCarthy, Department of Chemistry, North Dakota State University, Fargo, ND 58105

Abstract deadline: June 3 


\section{Symposium $Y$}

\section{FRONTIERS IN MATERIALS EDUCATION}

Materials science and engineering education is undergoing dynamic changes to meet the anticipated needs of materials professionals in the future. This symposium will provide a forum to address the important and pressing issues in materials science and engineering education. The symposium will be organized around broad philosophical views as well as specific focused issues. A workshop will be included to focus upon some of the key issues presented. Papers should focus on issues. Topics considered appropriate include, but are not limited to, the following:

- Current state of education in metals, ceramics, or polymers

- Core educational programs

- Graduate education core and/or philosophy

- Integrated materials programs

- Cross discipline programs

- Electronic materials

- Role of computers in undergraduate education

- Attracting qualified students

- University-industry cooperative programs

- Industry need and/or utilization of materials professionals

Symposium Chairpersons

G. L. Liedl, CMET Building, Purdue University, West Lafayette, IN 47907, (317) 494-4095

L. W. Hobbs, Dept. of Mat. Sci. and Engr., MIT, 13-4066, Cambridge, MA 02139, (617) 253-6835

\section{Symposium X}

\section{FRONTIERS OF MATERIALS RESEARCH}

$A$ series of authoritative reviews for the non-specialist

This luncheon-time series will consist of 35-40 minute lectures, given by leaders in a field, of a definitely didactic nature, designed to give nonspecialists an overview of the latest developments in one of the frontier areas of materials research. Two such lectures will be given during the luncheon period, at 12:05-12:45 and 12:45-1:25 each day Monday through Friday, December 2-6.

These lectures will subsequently be made widely available at minimum cost to students all over the world since they will be published in the Journal of Materials Education, as part of the NSF Project EMMSE, a not-for-profit educational venture developed by the worldwide materials science community.

Symposium Chairperson

Rustum Roy, Director, Materials Research Laboratory, The Pennsylvania State University, University Park, PA 16802, (814) 865-3421

\section{For further information on Fall Meeting Call for Papers}

To obtain a complete Call for Papers announcement of the 1985 MRS Fall Meeting, Boston, December 1-6, 1985, with instructions for abstracts and manuscripts, return this form to Materials Research Society, 9800 McKnight Road, Suite 327, Pittsburgh, PA 15237, telephone (412) 367-3003.

Name

Organization

Address

City

Postal Code

Country

Member MRS-Europe 